IJIET, e-ISSN 2548-8430, p-ISSN 2548-8422, Vol. 1, No. 1, January 2017

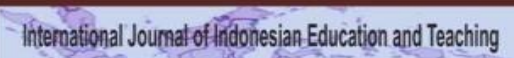

IJIET

International Journal of Indonesian Education and Teaching http://e-journal.usd.ac.id/index.php/IJIET

Sanata Dharma University, Yogyakarta, Indonesia

\title{
TOLERATING STRUCTURAL AMBIGUITY IN GRAMMAR LEARNING
}

\author{
Monika Dini Kurniasari Sanata Dharma \\ University monikadini.md@gmail.com \\ https://doi.org/10.24071/ijiet.v1i1.330
}

\begin{abstract}
Teaching grammar is believed to be a way to help learners use English correctly and appropriately. However, as English teachers, we sometimes find that a word, phrase, or sentence is ambiguous as it has more than one meaning. The ambiguity, however, can be noticed if one really has a linguistic knowledge on how to analyze the phrase or sentence. There are two kinds of ambiguity (lexical and structural). This paper explores structural ambiguity. Structural ambiguity occurs when a phrase or sentence has more than one underlying structure. The phrase can be disambiguated by putting it in a sentence with some sort of formal indicator which helps the reader or hearer to recognize the sentence structure. Some of the signals include function words, inflections, affixes, stress, juncture, and punctuation. The rest of this paper discusses some types of structural ambiguity, how they differ, and some possible ways to resolve them in order to have understanding for the learners.
\end{abstract}

Keywords: grammar, ambiguity, sentences

\section{Introduction}

One of important things in life is language. People communicate to others by using language. They communicate with each other either spoken or written. But, sometimes people do not get what we have said to them. It is not because they do not hear it, but, it is because we utter a sentence which has more than one meaning. As the consequence, the listeners will have (some) different interpretations and this will make confusion for the listener. In this case, this misunderstanding is called an ambiguity.

Ambiguous sentences can be found in any circumstances. We may find it not only when people say something to us but we can also find ambiguous sentences in written forms, like in the books, newspapers, magazines, and so on. Ambiguous sentences occur if there is more than one meaning which can be interpreted by the people who read or listen to it.

There are three kinds of ambiguity according to Ullmann (as cited in Tambunan 202, 204); phonetic, grammatical or structural, and lexical ambiguity. According to Hurford and Hesly (1983:128), there are 2 (two) groups of ambiguity: lexical and structural ambiguity. Moreover, Kess (1992:133) classifiedambiguity to be in 3 (three) groups. They are lexical ambiguity, surface structure ambiguity and deep (underlying) structure ambiguity. 
As described above, this paper simplifies ambiguity into 2 (two) categories. They are lexical and structural ambiguity. Furthermore, ambiguity, either lexical or structural, contains two or more possible meanings. Principally, when a sentence has more than one reading, it is an ambiguous sentence.

Davidson (1975:18) explains a theory of semantics of a natural language aims to give the meaning of every meaningful expression, but it is a question whatform a theory should take if it is to accomplish this. Since there seems to be no clear limit to the number of meaningful expressions, a workable theory must account for the meaning of each expression on the basis of the patterned exhibition of a finite number of features. But even if there were a practicalconstraint on the length of the sentences a person can send and receive with understanding, a satisfactory semantics would need to explain the contribution of repeatable features to the meaning of sentences in which they occur.

As described by Marckwardt (1966: 67), as we come to deal with composition, literature, and reading, we shall see that language, though important, is not always the sole factor, and we must be prepared to see this reflected in the size and nature of the part that linguistics plays. Teaching values: the student must know how to express himself cogently and articulately in order to perform effectively in the rest of his school subjects, to write papers and reports, to take examinations, and so on. This would be achieved though guided practice. Based on this idea, this paper emphasizes on how to tolerate structural ambiguity in grammar learning. This paper overviews five ambiguous sentences to be included in the discussion. Here are the 5 (five) samples of ambiguous sentences: (1) Visiting aunties can be boring. (2) The teacher thanked the students who had given her some flowers. (3) I saw a girl with a telescope. (4) Sam loves the babies more than Katy. (5) Put the tumbler on the table in the kitchen.

\section{Previous Studies}

In Teachers Training and Education Faculty and Literature Faculty of Sanata Dharma University, there have been four undergraaduate theses discussing about ambiguity. The first thesis is by Ni Putu Vitria Arizona (2016), The Lexical Ambiguity in Cosmetics Advertisement investigates the lexical ambiguity in cosmetics advertisement and then sees the readers' interpretation toward it. The second thesis is by Mutiara Sekar Utami (2013), Investigating lexical and structural ambiguity in the reader's forum of the Jakarta Post Newspaper which contains lexical or structural ambiguity analysis in one of rubric in Jakarta Post Newspaper. The third thesis is An investigation of structural ambiguity in phrases found in Indonesian authors 'fan-fiction products by Rosa Wuri Amurti (2012). The fourth thesis is The Analysis of Moral Ambiguity Seen in Long Martha Silver's Characterization in Robert Louis Stevenson`s Treasure Island by Ronny Santoso (2011).

The difference between those four theses from the writer's paper is that the writer focuses on structural ambiguity found in grammar learning. This paper overviews five ambiguous sentences to be included in the discussion as mentioned above. 
Ambiguity means (an example of) the fact of something having more than one possible meaning and therefore possibly causing confusion (http://dictionary.cambridge.org/dictionary/english/ambiguity). According to Bloomer (2006: 22), ambiguity also occurs at the syntactic level. It entails two or more possible interpretations of the structure of a clause, as in Hubert saw his grandmother with a telescope. Syntactic ambiguity is of interest because it can tell us how our grammatical and semantic processing interacts. If we interpret a whole clause grammatically before we try to interpret it, then we should not expect to find any evidence of the semantic context having resolved the disambiguation before the clause has ended. Syntactic ambiguity, also called amphiboly or amphibology, is a situation where a sentence may be interpreted in more than one way due to ambiguous sentence structure.

Empson (1955: 4) further explains an ambiguity, in ordinary speech, means something very ponounced, and as a rue wittyand deceitful. Ambiguity must be distinguished from vagueness, although it is not always easy to decide whether a specific case of unclear meaning is one or the other. Ambiguous expressions have more than one distinct meaning; vague expressions have a single meaning that cannot be characterized precisely. (It is of course possible for an expression to be both ambiguous and vague, if it has multiple meanings, at least one of which cannot be made precise). If expressions are thought of as picking out regions in some semantic space, then ambiguous expressions pick out more than one region, whereas vague expressions pick out regions with fuzzy boundaries.

Not all ambiguities can be tied to specific lexical items. Structural ambiguities arise when a given string of words can be parsed in two different ways, with different meanings. Clear examples of this occur with coordinateconstructions, where modifiers or complements on either periphery of the construction can be associated with either the whole coordination or just the adjacent conjunct. Let us see these examples:

1. The guards let small men and women exit first.

2. Teachers and students of the speaker received priority seating.

In (1), small may modify just men or men and women, and in (2) of the speaker may be the complement of just students or of teachers and students.

The first category of ambiguity is lexical ambiguity. Lexical ambiguity is the effect of an ambiguity of a word. One example is this following sentence: They went to the bank. The word "bank" in this sentence has two possiblemeaning. The first possible meaning is the edge of a river. The second possible meaning is financial institution. From this example, it is not easy to get the meaning of "bank". Additionally, it needs a further context to illustrate the implication of the sentence. This sentence is ambiguous as a result of the lackness of information. This sentence can be disambiguated by as long as additional information as in. Therefore, the disambiguated sentence is "They went to thebank to save some money".

In English grammar, syntactic ambiguity is the presence of two or more possible meanings within a single sentence or sequence of words. It is also called structural ambiguity or grammatical ambiguity. Ambiguity, that arises from the fact that two or more different syntactic structures, can be assigned to one string 
of words. The phrase old men and women is structurally ambiguous because it has the following two structural analyses:

(a) old [men and women]

(b) [old men] and women

Ambiguous expressions that are not structurally ambiguous display lexical ambiguity. The concept of ambiguity is generally contrasted with vagueness. In ambiguity, specific and distinct interpretations are permitted (although some may not be immediately obvious), whereas with information that is vague, it is difficult to form any interpretation at the desired level of specificity. Context may play a role in resolving ambiguity. For example, the same piece of information may be ambiguous in one context and unambiguous in another.

Ambiguous words or statements lead to vagueness and confusion, and shape the basis for instances of unintentional humor. For instance, it is ambiguous to say "I rode a black horse in red pajamas," because it may lead us to think the horse was wearing red pajamas. The sentence becomes clear when it is restructured "Wearing red pajamas, I rode a black horse."

Similarly, same words with different meanings can cause ambiguity, like in "Ron took off his trousers by the bank." It is funny if we confuse one meaning of "bank" which is a building, to another meaning, being "an edge of a river". Context usually resolves any ambiguity in such cases.

Crystal elaborates that phrase is a term used in grammatical analysis to refer to a single element of structure containing more than one word and lacking the subject-predicate structure typical of clauses. Furthermore, he classifies 5 (five) types of phrases which are noun phrase, verb phrase, adverbial phrase, adjectival phrase and prepositional phrase (1980: 170).

Crystal (1980:319) explains that sentence is the largest structural unit in terms in which the grammar of a language is organized. Additionally, he distinguishes sentence into four types: statement, question, command and exclamatory.

\section{Method}

The aim of this study is to describe structural ambiguity through 5 (five) sentences. The writer uses 5 (five) sample of sentences which most likely contain ambiguous meaning and she will analyze them based on the structural ambiguity. This research is a qualitative study. The data of this study are collected by using: sample. The sample sentences are analyzed though structural analysis.

\section{Structural Analysis}

Structural analysis and its main concern are to investigate the distribution of forms in a language. The method involves the use of "test-frames" that can be sentences with empty slots in them as it is explained by Yule (2010:90). For example:

$$
\begin{array}{ll}
\text { The } & \text { makes a lot of noise. } \\
I & \text { heard a yesterday. }
\end{array}
$$

There are a lot of forms that can fit into these slots to produce good grammatical sentences of English (e.g. car, child, donkey, dog, radio). As a result, we can propose that because all these forms fit in the same test-frame, they are likely to 
be examples of the same grammatical category. The label we give to this grammatical category is, of course, "noun." Furthermore, the sample sentences are about to describe by using syntactic analysis.

Symbols used in syntactic analysis

This paper uses some list of common symbols and abbreviations that are summarized as follows:

\begin{tabular}{|c|c|c|}
\hline S sentence & NP noun phrase & PN proper noun \\
\hline $\mathrm{N}$ noun & VP verb phrase & Adv adverb \\
\hline V verb & Adj adjective & Prep preposition \\
\hline Art article & Pro pronoun & $\mathrm{PP}$ prepositional phrase \\
\hline $\begin{array}{l}\text { * ungramm } \\
\rightarrow \text { consists } \\
\text { ( ) optional }\end{array}$ & $\begin{array}{l}\text { ence } \\
\text { es as }\end{array}$ & \\
\hline
\end{tabular}

\section{Findings and Discussion}

\section{Types of Structural Ambiguity}

From many types of structural ambiguity, 5 (five) sentences are explored in this paper only include:

Type 1 : Gerund + VP

Type $2: \mathrm{NP}+$ Adj. Clause

Type $3: \mathrm{VP}+\mathrm{NP}+\mathrm{PP}$

Type $4: \mathrm{VP}+\mathrm{NP}+$ more...than $+\mathrm{NP}$

Type $5: \mathrm{VP}+\mathrm{NP}+\mathrm{PP} 1+\mathrm{PP} 2$

Type 1: Gerund + VP

Sample sentence (1) Visiting aunties can be boring.

Visiting aunties can be boring.

$$
\text { Gerund VP }
$$

The second type of ambiguity has the construction a gerund followed by a verb. The example sentence is ambiguous because 'visiting aunties' can be understood in two ways: as a compound noun and as a noun phrase consisting of a modifier plus a noun. In writing, it is hard to eliminate the ambiguity, but in speaking, it can be cleared up by using intonation pattern. When it is pronounces with / $2-31 \uparrow /$ pattern, the utterance indicates a compound noun, which means 'the action of visiting aunties'. However, when it is pronounced with / $32-1 \uparrow /$ pattern, the utterance implies a noun phrase, which means 'relatives who visit'.

Below are other examples which also indicate ambiguity of a compound noun and a noun phrase (taken from Simatupang, 2007: 101).

$>$ Flying object:

An object to fly

An object that flies

Moving car:

A carfor moving 
A car that moves

Type 2: NP + Adj. Clause

Sample sentence (2): The teacher thanked the students who had given her some flowers.

The teacher thanked the students who had given her some flowers. NP Adj. Clause

This fifth sentence can be ambiguous because it can be written in two versions with absolutely different meaning:

a) The teacher thanked the students who had given her some flowers.

b) The teacher thanked the students, who had given her some flowers.

In spoken language, the first sentence is uttered without juncture, while the second with juncture between the antecedent (NP) and the Adjective clause. The interpretation of the first sentence, the adjective clause 'who had given her some flower' restrict NP 'the student' to give important information 'which students' the teacher thanked. It implies that the teacher thanked only some students who had given her some flowers (not those who didn't give her flowers). The adjectiveclause in the second sentence does not restrict the antecedent 'the student', thus, it gives further information which is not needed to identify the person. It means that the teacher thanked all of the students (and all of them gave her flowers). This shows the importance of proper punctuation in writing, and juncture in spoken utterance.

For Indonesian learners, however, the different meaning of restricted and non restricted adjective clauses is still a problem unless their linguistic knowledgeis adequate. Here are some other examples:

Carl got into the car which was parked behind the house:

There are many cars parked behind the house.

$>$ Carl got into the car, which was parked behind the house:

There is only one car parked behind the house.

$>$ In Indonesian Idol Contest, Joy waved her hands to her fans who shouted at her: (Joy waved her hands only to some of her fans.)

$>$ In Indonesian Idol Contest, Joy waved her hands to her fans, who shouted at her: (Joy waved her hand to all of her fans.)

Type 3: VP + NP + PP (prepositional phrase)

Sample sentence (3) I saw a girl with a telescope.

$\frac{\mathrm{I}}{\mathrm{VP}} \quad \frac{\text { saw }}{\mathrm{NP}} \quad \frac{\text { a girl with a telescope }}{\mathrm{PP}}$

The sentence may mean 'Somebody was seeing a girl by using a telescope' or 'somebody was seeing a girl who is holding or bringing a telescope'. This type of ambiguity occurs since the prepositional phrase 'with a telescope' can modify two nouns 'I' or a 'girl', either of which can be treated as its antecedent. In the sentence there is no clue to which noun the PP modifies. In other words, 'with a telescope' can modify the nouns of 'I or a girl'. This type of structural ambiguity 
results from the lack of information in the construction. If additional information is added to it, the sentence becomes unambiguous:

a) I saw a girl with a telescope. The telescope is broken.

b) I saw a girl with a telescope. The girl is pretty.

In a), 'with a telescope' refers to 'I'; and in b), to 'a girl'. Other examples of the same sort (prepositional phrase that can modify two noun phrases) are:

$>$ The girl hit the boy with a book:

Using a book, the girl hit the boy.

The boy is bringing a book when the girl hit him.

$>$ Jimmy harms Mira with a cutter:

Using a cutter, Jimmy harms Mira.

Mirais holding a cutter when Jimmy harms her.

Type 4: VP + NP + more ... than + NP

Sample sentence (4): Sam loves the babies more than Katy.

$\underline{\text { Sam loves }}$ the babies more than Katy
$\mathrm{VP}$
NP
NP

This third type of ambiguity concerns comparative degree. It is ambiguous because the shortened version may function as the subject of the second (shortened) clause or as the object of the verb 'love' which is in comparative relation with 'the babies'. The rule is if the comparative clause is identical to the main clause except for a contrasted phrase; optionally remove everything from the comparative clause except for this contrasted phrase. In other words, when one makes a sentence using comparative degree, he/she will use the sentence, for instance, 'Linda hates Karin more than Eric', rather than 'Linda hates Karin more than he hates Eric' to avoid repetition of similar words. From the example of type 3 above, because of the removal of similar words, the sentence has two meanings.

a) Sam loves the babies more than Katy loves the babies.

b) Sam loves the babies more than He loves Katy.

To make it unambiguous, the shortened version should be added somemissing information. The shortened version of 'Sam loves the babies more than Katy loves the fans' should be 'Sam loves the babies more than Katy does'. If we mean 'Sam loves the babies more than He loves Katy', the sentence cannot be shortened.

The followings are other examples of ambiguity of comparative clauses:

$>$ Martha listens to jazz music more often than her mom:

Martha listens to jazz music more often than her mom listens to jazz music.

Martha listens to jazz music more often than he listens to her mom.

$>$ Harry loves Aurel more than Louis:

Harry loves Aurel more than Louis loves Aurel.

Harry loves Aurel more than Harry loves Louis.

Type 5: VP + NP + PP1 + PP2

Sample sentence (5): Put the tumbler on the table in the kitchen.

$\frac{\text { Put }}{\text { (VP) }} \frac{\text { the tumbler }}{\text { NP }} \frac{\text { on the table }}{\text { PP1 }} \frac{\text { in the kitchen }}{\text { PP2 }}$ 
The sentence above is ambiguous since the first modifier 'on the tumbler' can modify the closest NP or PP2. It is not clear whether 'on the table' modifies 'the tumbler' or 'in the kitchen'. If it modifies 'the tumbler', it means that the bottle is already on the table and should be put in the kitchen. On the other hand, if it modifies 'in the kitchen', it means that the tumbler should be put from somewhere else to the table which is in the kitchen.

The ambiguity can be resolved by placing a terminal juncture between the first and the second modifier. Thus, the sentence may mean 'Put the tumbler on the table / in the kitchen'. The juncture shows that the tumbler is already on the table and then to be put in the kitchen. The second interpretation, is 'Put the tumbler / on the table in the kitchen'. It means that the tumbler should be put on the table, and the location of the table is in the kitchen (not the table in the bedroom).

The followings are other examples of ambiguity with two modifiers.

$>$ Place the hat in the drawer in the bed room:

To place the hat inside the drawer, this is located in the bedroom.

The hat is already in the drawer and should be placed in the bedroom.

$>$ Put the book on the box in that room:

To put the book on the box, this is located in that room.

The book is already on the box, and it should be put in that room.

Piantadosi, et al point out that there are many features that can contribute to the amount of effort involved in using a word. These include length, phonotactic complexity, and number of phonologically and/or semantically similar words. It is easier for language learners, as well as for speakers and hearers, if words that are easy on these dimensions are used frequently. This can include using one form for multiple meanings, so long as the meanings are sufficiently distant from one another to make confusion regarding which is intended relatively rare. This reasoning predicts that properties like word length and phonotactic complexity should correlate negatively with number of meanings. Piantadosi, et al test severalsuch predictions against dictionaries of English, German, and Dutch, getting generally confirmatory results.

\section{Conclusion}

We sometimes do not know if a sentence has a clear message or ambiguity. Whether or not we recognize the ambiguity depend on our linguistic knowledge. For English learners, however, it is still not easy to know if a sentence is ambiguous or not. Having adequate proficiency of English, we are aware of the ambiguity, and try to avoid them, if possible. In writing, for example, we need to use some formal signals (e.g. punctuation) to tolerate ambiguous sentences.

The five types of ambiguity presented in this paper are only some examples of some types of structural ambiguity. Piantadosi, et al (as cited from Wasow (2015:12) provide another simple, but persuasive, explanation of why languages are ambiguous. To achieve maximal efficiency as a medium of communication, a language should not convey unnecessary information. (Recall Grice's Maxim of 
Quantity, half of which says: "Do not make your contribution more informative than is required.") Since the context of use generally contributes a considerable amount of information about what the speaker is likely to be talking about, utterances should omit such information. Consequently, many sentences, taken in isolation, are ambiguous, although hearers have no difficulty in understanding what meaning was intended on particular occasions when they are used.

There is, however, one aspect of meaning in which ambiguity is characteristically avoided, namely, argument structure - who did what to whom. Evidently, this is such acentral component of what is communicated that it is normally obligatorily marked - at least in simple declarative clauses without ellipsis. But, as noted above, ambiguities do arise even in this domain. So although grammars contain mechanisms to minimize this one type of ambiguity, ambiguity avoidance is widely overrated as a factor in language structure and use. As stated by Mckay (1985: xix) the purpose of grammar learning is the variety of realistic situations in order to learn to communicate effectively. Thus, tolerating structural ambiguty in grammar learning means getting better understanding of theEnglish language.

\section{References}

Bloomer, A. (2006). Projects in Linguistics: A Practical Guide to Reserching Language. London: Hodder Arnold.

Crystal, D. (1980). A First Dictionary of Lingusitics and Phonetics. Cambridge: Cambridge University Press.

Davidson, S \& Harman, G. (1975). The Logic of Grammar. California: Dickenson Publishing.

Empson, W. (1955). Seven types of ambiguity. NewYork: The Noonday Press.

Grice, H. Paul (1975) "Logic and Conversation". In P. Cole and J. Morgan (eds.) Syntax and Semantics 3: Speech Acts. pp. 26-40. New York: Academic Press.

Hurford, James R. 1983. Semantisc: A Coursebook. Cambridge: Cambridge University Press.

Kess, Joseph F. 1992. Psycholinguistics: Psychology, Linguistics and the Study of Natural Language. Amsterdam: John Benjamins Publishing Company.

Marckwardt, A.H. (1966). Linguistics and the teaching of English. Bloomington London: Indiana University Press.

McKay, S.L. (1985). Teaching Grammar: From,Fucntion and Technique. New York: Pergamon Press.

Simatupang, M.S. (2007). How Ambiguous is the Structural Ambiguity. Jurnal LINGUA CULTURA Vol.1 No.2 November 2007: 99-104. Retrieved on October 13, 2106 from journal.binus.ac.id/index.php/lingua/article/ viewFile/315/299

Tambunan, H.A. (2009). The Analysis of Lexical And Structural Ambiguity inYour Letter in Jakarta Post Newspaper. Retrieved on October 13, 2016 from library.uwp.ac.id/digilib/files/.../-diahpurwan-315-1-06100000-l.pdf 
IJIET Vol. 1, No. 1, January 2017

Wasow, T. (2015). Ambiguity Avoidance is Overrated. Stanford University.

Retrieved on October 13, 2106 from web.stanford.edu/ $\sim$ wasow/Ambiguity.pdf

Yule, G. The Study of Language (Fourth Edition). Cambridge: Cambridge University Press. 